\title{
Avaliação da irritabilidade ocular induzida por ingredientes de cosméticos através do teste de Draize e dos Métodos HET-CAM e RBC
}

\author{
Andréa Martins da Nóbrega' \\ Eloisa Nunes Alves ${ }^{2}$ \\ Rosaura de Farias Presgrave ${ }^{3}$ \\ Isabella Fernandes Delgado ${ }^{4}$
}

\section{Resumo}

O teste de Draize, usado na determinação do potencial irritante ocular, é uma das metodologias in vivo mais combatidas pelos setores antivivisseccionistas. No entanto, não existem ainda hoje métodos alternativos considerados oficiais, havendo a necessidade de estudos adicionais nessa área do conhecimento. O objetivo deste estudo foi comparar efeitos de tensoativos no teste de Draize com aqueles obtidos no RBC e HET-CAM. Oito tensoativos foram avaliados in vivo e as mesmas substâncias foram ensaiadas no RBC (hemácias de sangue de carneiro) e HET-CAM (ovos SPF incubados por 10 dias). Os resultados nos permitem concluir que: (i.) RBC e HET-CAM são ensaios viáveis; (ii.) o HET-CAM tende a superestimar resultados; (iii.) dentre os dois métodos in vitro, o RBC apresentou melhor concordância com o teste de Draize. Para avaliação final quanto à aplicabilidade do RBC e HET-CAM será necessária realização de novos ensaios, contemplando número maior de ingredientes e produtos acabados.

Palavras-chave: Métodos alternativos. Irritação ocular. Controle da qualidade. Vigilância Sanitária. 3R's.

\footnotetext{
${ }^{1}$ Bolsista PIBIC/Fiocruz do Departamento de Farmacologia e Toxicologia. INCQS/FIOCRUZ.

${ }^{2}$ Mestre em Vigilância Sanitária, Tecnologista Sênior do Departamento de Farmacologia e Toxicologia. INCQS/FIOCRUZ.

${ }^{3}$ Doutora em Vigilância Sanitária, Tecnologista Sênior do Departamento de Farmacologia e Toxicologia. INCQS/FIOCRUZ.

${ }^{4}$ Doutora em Ciências, Tecnologista em Saúde Pública do Departamento de Imunologia. INCQS/FIOCRUZ. Av. Brasil 4365 - Manguinhos. Rio de Janeiro - CEP: 21040-900. Email: isabella.delgado@incqs.fiocruz.br.
} 


\section{Introdução}

Até meados do século XX, era comum a comercialização de uma diversidade de produtos que, além de não serem testados quanto a sua eficácia, colocavam em risco a saúde de seus consumidores. A literatura descreve diversos episódios que se tornaram marcos históricos e se relacionam à utilização de produtos que ganharam o mercado, sem antes terem sido devidamente avaliados sob o ponto de vista toxicológico. Nesse contexto, vale citar a tragédia do elixir de sulfanilamida, o uso de terapias fortificantes à base de Ra-226 e/ou Ra-228, ou ainda, a tragédia da talidomida (WAX, 1995; MACKLIS, 1990; BOTTING, 2002).

Os casos de agravos à saúde humana não eram restritos aos medicamentos. A lista de princípios ativos, hoje, sabidamente tóxicos, presentes em produtos para higiene pessoal e embelezamento era significativa. Há registros da comercialização de produtos à base de mercúrio, e outros contendo altas concentrações de ácidos, ou à base de cloreto de cobre e hidrato de cloro; ou ainda xampus, contendo em suas formulações substâncias carcinogênicas, como o tetracloreto de carbono (ILAR, 2004; COSTA, 2006). No entanto, foi o caso do cosmético da linha Lash Lure $^{\bigotimes}$, um corante para cílios e sobrancelhas usado em estabelecimentos de beleza, o que entrou para história da Toxicologia como uma das maiores tragédias resultante da comercialização de cosméticos de todos os tempos (WILHELMUS, 2001). Esse produto, à base de parafenileno de amina, deixou pelo menos 12 indivíduos cegos e causou a morte de uma mulher nos EUA. Foi exatamente nesse contexto de conscientização da necessidade de maior controle por parte das agências regulatórios que, em meados da década de 1940, surgiu o teste de irritação ocular de Draize (DRAIZE et al., 1944).

O teste de Draize (DRAIZE et al., 1944; KAY; CALANDRA, 1962) é um teste realizado em coelhos, que determina a irritação ocular induzida por medicamentos, cosméticos e outras substâncias químicas. Esse teste é controverso, considerado por alguns autores um exemplo de crueldade, assim como, um método que apresenta grandes limitações, sobretudo no que diz respeito às diferenças entre o olho do coelho e o olho humano e à subjetividade de sua resposta. Por esse motivo, é uma das metodologias in vivo mais combatidas pelos setores antivivisseccionistas e também um dos primeiros ensaios utilizados para fins regulatórios pelo qual se procuraram alternativas in vitro. 
Nas últimas décadas, vários grupos de pesquisadores vêm estudando e desenvolvendo métodos alternativos para determinação da irritação ocular (NORTH-ROOT et al., 1982; SHOPSIS; ENG, 1985; YANG; ACOSTA, 1994; VIAN et al., 1995; DE TORRES et al., 1997; TANI et al., 1999; ALVES et al., 2005; DEBBASCH et al., 2005; GERNER et al., 2005; LAGARTO et al., 2006; MEHLING et al., 2007; TAVASZI; BUDAI, 2007; ALVES et al. 2008; MITJANS et al., 2008; ADRIAENS et al., 2008; ABREU, 2008; TAKAHASHI et al., 2008). Como alternativas ao teste de Draize, podemos citar: teste em membrana corion-alantóide de ovo embrionado de galinha (HET-CAM), teste de opacidade e permeabilidade de córnea bovina (BCOP); teste em olho isolado de coelho (IRE); teste em olho enucleado de galinha (ICE); ensaios de citotoxicidade como o teste de hemólise (Red Blood Cell - RBC); ensaio de captação do vermelho neutro (NRU); ensaio de quantificação de proteínas totais (QPT); ensaio da atividade metabólica mitocondrial (MTT); e teste de liberação de IL-8, entre outros.

Apesar do teste de Draize ser um dos principais alvos dos grupos ativistas que lutam em defesa dos direitos dos animais, dos inúmeros estudos relacionados ao tema e da recente validação das metodologias de BCOP e ICE (olhos isolados de bovinos e de galinhas), tais ensaios ainda não têm aceitação regulatória, não sendo, portanto, consideradas oficiais (ESAC, 2009). No caso da avaliação da toxicidade ocular induzida por produtos, assim como em outras situações, acredita-se que um único método alternativo dificilmente será capaz de substituir o uso de animais. Assim, os principais centros internacionais de estudos e validação de métodos alternativos ao uso de animais, como e.g. ECVAM (European Centre for Validation of Alternative Methods) e ICCVAM (Interagency Coordinating Committee on the Validation of Alternative Methods) recomendam que a comunidade científica: (i.) continue a buscar novas metodologias; (ii.) aprofunde seus conhecimentos a respeito das metodologias pré-existentes, procurando conhecer as peculiaridades destes métodos e avaliando um maior número de substâncias/classes de substâncias; e, (iii.) sempre que possível, proponha protocolos que sejam sensíveis e reprodutíveis.

É nesse contexto que o presente estudo pretende contribuir, tendo como objetivo comparar os efeitos induzidos por tensoativos (i.e. uma classe de substâncias presente em produtos cosméticos) no teste de Draize e nos métodos HET-CAM e RBC. 


\section{Metodologia}

\section{Amostras:}

Foram avaliados 08 tensoativos: lauril éter sulfato de sódio a 27\% (TS02), cocoamido propilbetaína a 30\% (TS03), lauril poliglucosídeo (TS04) fornecidos gentilmente pela empresa Allergisa ${ }^{\circledR}$, lauril sulfato de sódio (TS01), cloreto de benzalcônio (TS05), triton-X-100 (TS08) e tween-20 (TS09) fornecidos pela Sigma e o brometo de cetildimetilamônio (TS06) fornecido pela Merk ${ }^{\circledR}$.

\section{Teste de Draize:}

Os dados relacionados ao teste in vivo são provenientes do banco de dados do Departamento de Farmacologia e Toxicologia do INCQS.

Os tensoativos foram aplicados em diferentes concentrações que variaram entre $0,5 \%$ e $100 \%$. O teste de Draize foi realizado conforme o Manual da Qualidade do INCQS/FIOCRUZ (Procedimento Operacional Padrão - POP - 653330.004), cujo objetivo é a detecção e avaliação do potencial de irritabilidade ocular para o homem, de qualquer substância ou produto acabado.

Para cada tensoativo, foram utilizados 5 coelhos da raça Nova Zelândia provenientes do Centro de Criação de Animais de Laboratório (CECAL/FIOCRUZ), machos ou fêmeas, hígidos e de peso corpóreo acima de $2 \mathrm{~kg}$. Instilou-se $0,1 \mathrm{ml}$ da amostra no saco conjuntival inferior e, em seguida, massageou-se gentilmente durante 30 segundos. As leituras foram realizadas nos períodos de 24, 48, 72 horas e 7 dias após a aplicação da amostra, para observar as alterações que podem ocorrer nas estruturas do olho (córnea, íris e conjuntiva) e calcular a média dos escores máximo (MEM) por substância analisada.

O teste de Draize permite as seguintes classificações: não irritante (NI), irritante leve (IL), irritante moderado (IM), irritante severo (IS) e irritante máximo (IMax).

Este estudo foi aprovado pela Comissão de Ética em Uso de Animais da Fiocruz (protocolos CEUA/Fiocruz P.0137-02 e P.0148-02). 


\subsection{Ensaio RBC}

Esta etapa do estudo foi realizada conforme Pape (1992).

- Procedimento: As amostras de sangue desfibrinado de carneiro foram provenientes do CECAL/FIOCRUZ.

- Isolamento das hemácias: Um concentrado de hemácias foi adquirido por meio da centrifugação do sangue a uma velocidade de $1302 \mathrm{~g}$ durante 15 minutos. O sobrenadante foi retirado e três lavagens foram realizadas com tampão fosfato-salina (PBS), para a retirada de traços de plasma e de outras impurezas.

- Estocagem das hemácias: As hemácias foram estocadas numa concentração de $8,0 \times 10^{9}$ células $/ \mathrm{ml} \mathrm{em} \mathrm{PBS} \mathrm{e} \mathrm{acondicionadas} \mathrm{em}$ microtubos com capacidade de $1,5 \mathrm{ml}$ e conservadas à temperatura de $4^{\circ} \mathrm{C}$ por um período de 4 semanas.

- Estudo da $\mathrm{IC}_{50}$ : Os tensoativos foram diluídos em PBS nas concentrações 0,$0001 ; 0,001 ; 0,01 ; 0,1 ; 1 ; 10 ; 100 \mathrm{mg} / \mathrm{ml}$. Aliquotouse $975 \mu \mathrm{l}$ de cada diluição e adicionou-se $25 \mu \mathrm{l}$ da suspensão de hemácias, homogeinizando e incubando por 10 minutos, em temperatura e agitação constante, seguido de rápida centrifugação a $7520 \mathrm{~g}$ durante 1 minuto. O sobrenadante foi retirado para leitura no espectrofotômetro no comprimentos de onda de $540 \mathrm{~nm}$ contra o branco (substância-teste diluída em PBS).

\subsection{Hemólise}

- Foram avaliadas 8 concentrações crescentes (10, 20, 30, 40, 50, 60, $70,80 \mu \mathrm{l})$ de cada tensoativo a partir de solução mãe a $1 \mathrm{mg} / \mathrm{ml} \mathrm{em}$ PBS, sendo cada microtubo completado com volume de PBS até $975 \mu$;

- Incubou-se com o volume definido de $25 \mu \mathrm{l}$ da suspensão de hemácias por 10 minutos, com agitação constante em temperatura ambiente; 
- Centrifugou-se a $7520 \mathrm{~g}$ durante 1 minuto;

- O sobrenadante foi lido em espectrofotômetro no comprimento de onda de 540nm contra o branco. As leituras obtidas foram comparadas com a leitura do tubo totalmente hemolisado pela água destilada, de forma a calcular a concentração efetiva que causa $50 \%$ de hemólise $\left(\mathrm{H}_{50}\right)$.

\subsection{Desnaturação}

- Incubou-se $25 \mu \mathrm{l}$ da suspensão de hemácias com $975 \mu \mathrm{l}$ da solução mãe $(1 \mathrm{mg} / \mathrm{mL})$ por 10 minutos com agitação constante em temperatura ambiente; em seguida fazendo rápida (1 min.) centrifugação a 7520g;

- O sobrenadante foi lido no espectrofotômetro em comprimentos de ondas de 575 e $540 \mathrm{~nm}$ contra o branco;

- A partir desses resultados, foi calculado o Índice de Desnaturação (ID) obtido pela seguinte equação:

$$
\operatorname{ID}(\%)=100 .\left(\mathbf{R}_{1}-\mathbf{R}_{\mathrm{i}}\right) /\left(\mathbf{R}_{1}-\mathbf{R}_{2}\right)
$$

$\mathrm{R}_{1}$ - Hemolisado, $\mathrm{R}_{\mathrm{i}}$ - Substância - teste, $\mathrm{R}_{2}$ - SDS a $0,1 \%$

- A razão $\mathrm{H}_{50} / \mathrm{ID}$ para cada substância-teste foi empregada para classificação dos produtos, quanto ao seu potencial de irritação, conforme Tabela 1.

Tabela 1 - Classificação final das amostras quanto ao seu potencial de irritação no Ensaio RBC.

\begin{tabular}{rc}
\hline Faixa $\left(\mathrm{H}_{50} / \mathrm{ID}\right)$ & Classificação \\
\hline $\mathbf{1 0 0}$ & Não Irritante (NI) \\
$\mathbf{1 0}$ & Irritante Leve (IL) \\
$\mathbf{1 0}$ & Irritante Moderado (IM) \\
$\mathbf{2 0 , 1}$ & Irritante Severo (IS) \\
$<\mathbf{0 , 1}$ & Irritante Máximo (IMax) \\
\hline
\end{tabular}

* Todas as substâncias-teste foram avaliadas em triplicata. 
Tabela 2 - Graduação das alterações observadas na membrana córion-alantóie do ovo embrionado de galinha

\begin{tabular}{lccc}
\hline Fenômenos & $\mathbf{3 0}$ segundos & $\begin{array}{c}\text { Tempo } \\
\mathbf{3 0} \mathbf{s}<\mathbf{t} \leq \mathbf{2} \\
\text { minutos }\end{array}$ & $\begin{array}{c}\mathbf{2} \text { min }<\mathbf{t} \leq \mathbf{5} \\
\text { minutos }\end{array}$ \\
\hline Hiperemia & 5 & 3 & 1 \\
Hemorragia & 7 & 5 & 3 \\
Coagulação /Opacidade & 9 & 7 & 5 \\
\hline
\end{tabular}

\section{Ensaio HET-CAM}

O ensaio foi realizado de acordo com a metodologia descrita no Journal Officiel de la Republique Française (1996). Os tensoativos foram testados diluídos $(0,25 \%$ a $2 \%)$. Foram utilizados ovos SPF, fertilizados, de galinha da raça Leghorn, incubados por 10 dias a temperatura de $38^{\circ} \mathrm{C} \pm 5^{\circ} \mathrm{C}$ e umidade relativa de aproximadamente $70 \%$. Os ovos foram fornecidos pelo Setor de Febre Amarela, Bio-Manguinhos/FIOCRUZ. Para cada tensoativo foram utilizados 4 ovos.

No $10^{\circ}$ dia de incubação, foi retirada a casca do ovo ao redor da câmara de ar, evidenciando a membrana da casca. Após a membrana córion-alantóide ser exposta, foi aplicado sobre ela $300 \mu \mathrm{L}$ do produto que foi removido após 20 segundos de contato, lavando-se a membrana com solução salina isotônica a $37^{\circ} \mathrm{C}$. A membrana córion-alantóide foi examinada por cinco minutos e graduada para os efeitos irritantes, de acordo com a Tabela 2.

A média do somatório das graduações dos 4 ovos foi utilizada para determinar a classificação final do produto, conforme descrito na Tabela 3.

Tabela 3 - Classificação final do produto quanto ao seu potencial de irritação no HET-CAM

\begin{tabular}{cc}
\hline Faixa (Graduação das lesões) & Classificação \\
\hline $\mathbf{0 , 0}$ a 0,9 & Não Irritante (NI) \\
$\mathbf{1 , 0}$ a 4,9 & Irritante Leve (IL) \\
$\mathbf{5 , 0}$ a 8,9 & Irritante Moderado (IM) \\
$\mathbf{9 , 0}$ a 21 & Irritante Severo (IS) \\
\hline
\end{tabular}




\section{Resultados}

Os tensoativos foram avaliados em diferentes concentrações no teste in vivo. A relação dose-resposta e o potencial irritante ocular (MEM e classificação final) de cada tensoativo estudado estão demonstrados na Tabela 4.

Tabela 4 - Média do Escore Máximo (MEM) e classificação final obtidos com tensoativos no teste in vivo

\begin{tabular}{|c|c|c|c|c|c|c|c|c|}
\hline & \multicolumn{8}{|c|}{ Concentração aplicada nos olhos dos coelhos (\%) } \\
\hline & 100 & 30 & 16 & 10 & 8 & 4 & 1 & 0,5 \\
\hline TS09 & $\begin{array}{c}2,0 \\
(\mathrm{NI})\end{array}$ & - & - & - & - & - & - & - \\
\hline TS02 & - & $\begin{array}{l}26,8 \\
\text { (IM) }\end{array}$ & - & $\begin{array}{l}3,2 \\
(\mathrm{IL})\end{array}$ & - & - & - & - \\
\hline TS03 & - & $\begin{array}{l}31,0 \\
(\mathrm{IM}) \\
\end{array}$ & - & $\begin{array}{c}4,8 \\
\text { (IL) }\end{array}$ & - & - & - & - \\
\hline TS04 & - & - & - & $\begin{array}{l}5,2 \\
(\mathrm{IL})\end{array}$ & - & - & - & - \\
\hline TS01 & - & $\begin{array}{l}56,0 \\
(I S)\end{array}$ & $\begin{array}{l}48,4 \\
\text { (IS) } \\
\end{array}$ & $\begin{array}{l}15,6 \\
(\mathrm{IM}) \\
\end{array}$ & $\begin{array}{l}15,6 \\
(\mathrm{IM}) \\
\end{array}$ & $\begin{array}{l}5,6 \\
\text { (IL) } \\
\end{array}$ & - & - \\
\hline TS08 & - & $\begin{array}{c}59,8 \\
\text { (IMax) }\end{array}$ & - & - & - & - & $\begin{array}{l}2,8 \\
\text { (IL) }\end{array}$ & $\begin{array}{l}1,6 \\
(\mathrm{NI})\end{array}$ \\
\hline TS05 & - & - & - & - & - & - & $\begin{array}{l}46,4 \\
\text { (IS) }\end{array}$ & $\begin{array}{c}6,0 \\
(\mathrm{IM})\end{array}$ \\
\hline TS06 & - & - & - & - & - & - & - & $\begin{array}{c}8,4 \\
(\mathrm{IM})\end{array}$ \\
\hline
\end{tabular}

* TS01- lauril sulfato de sódio, TS02- lauril éter sulfato de sódio a $27 \%$, TS03- cocoamido propilbetaína a 30\%, TS04-lauril poliglucosídeo, TS05- cloreto de benzalcônio, TS06 brometo de cetildimetilamônio, TS08 - triton-x-100 e TS09- tween-20.

A partir dos resultados obtidos in vivo (Tabela 4), buscamos categorizar os tensoativos de acordo com o seu potencial irritante, como mostra a Tabela 5.

Os dados compilados nas Tabelas 4 e 5 demonstram que todos os tensoativos apresentam potencial irritante ocular, com exceção do tween-20 (TS09), um tensoativo não-iônico que, mesmo quando testado puro, foi classificado como não irritante. 
Tabela 5 - Categorização do potencial irritante ocular dos tensoativos avaliados.

\begin{tabular}{llcc}
\hline Tensoativos & Natureza & $\begin{array}{c}\text { Resultado in vivo: } \\
\text { Concentração teste } \\
\text { (Classificação) }\end{array}$ & $\begin{array}{c}\text { Potencial irritante } \\
\text { in vivo }\end{array}$ \\
\hline TS09 & Não-iônico & $100 \%(\mathrm{NI})$ & - \\
\hline TS02 & Aniônico & $30 \%(\mathrm{IM}) ; 10 \%(\mathrm{IL})$ & + \\
TS03 & Anfotérico & $30 \%(\mathrm{IM}) ; 10 \%(\mathrm{IL})$ & + \\
TS04 & Aniônico & $10 \%(\mathrm{IL})$ & + \\
\hline TS01 & Aniônico & $30 \%(\mathrm{IS}) ; 10 \%(\mathrm{IM})$ & ++ \\
\hline TS08 & Não-iônico & $30 \%(\mathrm{IMax}) ; 0,5 \%$ & +++ \\
\hline TS05 & Catiônico & $(\mathrm{NI})$ & ++++ \\
TS06 & Catiônico & $0,5 \%(\mathrm{IM})$ & ++++ \\
\hline
\end{tabular}

* TS01- lauril sulfato de sódio, TS02- lauril éter sulfato de sódio a $27 \%$, TS03- cocoamido propilbetaína a 30\%, TS04-lauril poliglucosídeo, TS05- cloreto de benzalcônio, TS06 brometo de cetildimetilamônio, TS08 - triton-x-100 e TS09 - tween-20.

A avaliação do potencial irritante ocular dos tensoativos lauril éter sulfato de sódio (TS02) e cocoamido propilbetaina (TS03) partiu de alíquotas previamente diluídas a $27 \%$ e $30 \%$, respectivamente. Nessas condições experimentais, esses tensoativos apresentaram potencial irritante moderado na maior concentração testada (30\%). Essas amostras, assim como o lauril poliglucosídeo (TS04), induziram lesões compatíveis com a classificação de irritante leve, quando avaliadas na concentração de $10 \%$.

O lauril sulfato de sódio (TS01) foi avaliado em diversas concentrações e mostrou-se irritante severo nas concentrações de 30\% e 16\%, tendo sido classificado como moderado nas concentrações de $10 \%$ e $8 \%$. Assim, pode-se dizer que, o lauril sulfato de sódio (TS01) apresentou maior potencial irritante para os olhos dos coelhos que os tensoativos TS02, TS03 e TS04, conforme demonstrado na Tabela 5.

O triton-X-100 (TS08) induziu lesões graves nos olhos dos animais. Esse tensoativo recebeu classificação compatível com “irritante máximo", quando aplicado nos olhos dos coelhos na concentração de 30\%, demonstrando assim que, apesar de pertencer à classe de tensoativos não-iônicos (que via de regra é considerada uma classe que compreende ingredientes com baixo potencial irritante), é mais irritante para os olhos que os tensoativos aniônicos lauril éter (TS02) e lauril sulfato de sódio (TS01). 
Os tensoativos que demonstraram os maiores potenciais irritantes foram os catiônicos cloreto de benzalcônio (TS05) e brometo de cetildimetiletilamônio (TS06). Estes ingredientes, mesmo quando avaliados em concentrações muito baixas (e.g. 0,5\%), induziram lesões oculares compatíveis com a classificação de “irritante moderado" (Tabelas 4 e 5).

Assim, considerando a classificação do teste de Draize em função da relação dose-resposta observada, podemos ordenar os tensoativos de acordo com o seu potencial irritante ocular in vivo; onde [TS09] $<$ [TS02 = TS03 = TS04 $]<[$ TS01 $]<$ [TS08 $]<$ [TS05 = TS06 $]$, conforme demonstra a Tabela 5 .

Uma análise comparativa dos resultados obtidos in vivo e nos testes in vitro está descrita a seguir e demonstrada na Tabela 6.

Tabela 6 - Comparação dos resultados dos testes in vitro e in vivo obtidos com tensoativos

\begin{tabular}{ccccc}
\hline Tensoativos & Natureza & $\begin{array}{c}\text { Potencial irritante } \\
\text { in vivo }\end{array}$ & $\begin{array}{c}\text { Resultado } \\
\text { HET-CAM }\end{array}$ & $\begin{array}{c}\text { Resultado } \\
\text { RBC }\end{array}$ \\
\hline TS09 & Não-iônico & - & IM & NI \\
\hline TS02 & Aniônico & + & IS & IM \\
TS03 & Anfotérico & + & IM & IL \\
TS04 & Aniônico & + & IS & IL \\
\hline TS01 & Aniônico & ++ & IS & IS \\
\hline TS08 & Não-iônico & +++ & IS & IM \\
\hline TS05 & Catiônico & ++++ & IS & IS \\
TS06 & Catiônico & ++++ & IS & IMax \\
\hline
\end{tabular}

* TS01- lauril sulfato de sódio, TS02- lauril éter sulfato de sódio a $27 \%$, TS03- cocoamido propilbetaína a 30\%, TS04-lauril poliglucosídeo, TS05- cloreto de benzalcônio, TS06 brometo de cetildimetilamônio, TS08 - triton-x-100 e TS09- tween-20.

\subsection{Método HET-CAM}

O método HET-CAM não foi capaz de diferenciar o único ingrediente não irritante deste estudo (TS09), assim como não distinguiu adequadamente os tensoativos quanto aos graus de severidade das reações por eles induzidas (Tabela 6). Seis dos oito (75\%) tensoativos avaliados receberam a classifica- 
ção máxima (IS) do HET-CAM, demonstrando assim que esse método tende a superestimar resultados obtidos in vivo.

\subsection{Método RBC}

Neste estudo, observamos as cinco classificações possíveis do método RBC (NI, IL, IM, IS, IMax). A utilização do RBC permitiu a identificação do TS09 como não irritante, assim como dos tensoativos TS03 e TS04 como irritantes leves e do TS06 como irritante máximo. Esses resultados são compatíveis com os dados obtidos in vivo, demonstrando que dentre os dois métodos in vitro, o RBC foi o que apresentou melhor concordância com o teste de Draize.

\section{Discussão}

A pressão política exercida por setores ativistas que lutam em defesa dos direitos dos animais tem gerado grande impacto na pesquisa científica, sobretudo na área biomédica. Nesse contexto, pode-se dizer que diversos setores da indústria, e.g. cosméticos, imunobiológicos, fármacos entre outros, assim como órgãos governamentais de regulamentação e controle da qualidade de produtos, estão sob crescente pressão para,, sempre que possível, substituir a experimentação animal por metodologias alternativas. Como resultado desse esforço mundial no desenvolvimento/validação de metodologias alternativas, existe hoje um número considerável de ensaios validados e aceitos para fins regulatórios (ABREU et al., 2008). Tais métodos são aplicáveis ao controle da qualidade de produtos sujeitos à ação da Vigilância Sanitária e, via de regra, apresentam boa especificidade, sensibilidade e precisão.

Em algumas situações, existem métodos alternativos que podem substituir por completo o uso de animais (e.g. modelos de pele reconstituída para avaliação da irritação dérmica induzida por cosméticos ou os testes in vitro para detecção da presença de contaminantes pirogênicos em imunobiológicos, fármacos, parenterais de grande volume etc). Em outras circunstâncias, existem métodos alternativos que apresentam vantagens em termos de redução e/ ou refinamento da técnica que pretendem substituir, e.g. ensaio do linfonodo 
local murino (LLNA) para avaliação do potencial dermossensibilizante de xenobióticos ou o teste da inibição da ligação de toxina (ToBI) para avaliação da potência do componente tetânico. No entanto, existem ainda situações em que não há a perspectiva de obter-se um único método que se mostre válido, plenamente aplicável e que venha substituir por completo o teste in vivo. Essa parece ser a condição em que se encontra hoje o processo de substituição do teste de irritação ocular de Draize.

Os métodos BCOP e o ICE, embora recentemente validados pelo ECVAM, são somente aplicáveis à avaliação de produtos corrosivos ou com severo potencial irritante (ESAC, 2009), não se destinam, assim, à avaliação de produtos com baixo potencial irritante; o que seria de fato o interesse na área de controle da qualidade de produtos sujeitos à ação da Vigilância Sanitária (e.g cosméticos, como xampus, condicionadores, maquiagem, ou medicamentos de uso oftálmico, como colírios etc).

Na circunstância em que o teste em animais não possa ser substituído por um único método alternativo, o desenvolvimento de esquema de avaliação que envolva uma bateria de testes deve ser levado em consideração. A OECD 405 recomenda um sistema hierárquico no qual os animais somente sejam utilizados para a confirmação da ausência de toxicidade, reduzindo ao máximo o risco desses animais sofrerem quaisquer efeitos adversos (ABREU et al., 2008).

A irritação ocular ocorre por meio de uma variedade de mecanismos; alguns dos quais podem ser avaliados por desfechos in vitro. Por exemplo, efeitos induzidos sobre células epiteliais da córnea ou da conjuntiva podem resultar em citotoxicidade direta ou alterar certas funções celulares, como a permeabilidade da membrana celular, um fenômeno facilmente avaliado in vitro. Outro desfecho passível de avaliação in vitro é o fenômeno da opacificação da córnea que, frequentemente, é induzida in vivo como resultado de processo inflamatório do tecido conjuntivo e do estroma corneal (ALVES et al., 2008). Esses e outros exemplos demonstram que existem diversas alternativas possíveis para avaliação do potencial irritante, entre elas o RBC e o HET-CAM (DE TORRES et al., 1997; TANI et al., 1999; DEBBASCH et al., 2005; TAVASKI; BUDAI, 2007; TAKAHASCHI et al., 2008). 
Nossos dados indicam que o RBC é superior ao HET-CAM, no que tange à diferenciação entre tensoativos irritantes e não-irritantes e ainda à classificação do potencial irritante ocular de tensoativos. Esses resultados estão de acordo com estudos publicados recentemente que mostram a boa aplicabilidade do RBC na avaliação da irritação ocular induzida por tensoativos (MEHLING et al., 2007; MITJANS et al., 2008) e produtos acabados (ALVES et al., 2008). O fato do método HET-CAM superestimar os resultados obtidos in vivo já havia sido descrito previamente (HAGINO et al., 1999; CORRADO, 2007) e se deve provavelmente a dois fatores principais.

O primeiro deles diz respeito às condições de exposição ao produto. Acreditamos que o fato de aplicar-se a substância-teste diretamente na membrana corion-alantóide, sem que haja nenhuma barreira protetora nesse tipo de exposição, seja um dos aspectos responsáveis pela maior sensibilidade do método HET-CAM, quando comparado ao modelo animal.

Outro fator importante nesse aspecto diz respeito ao próprio desfecho avaliado no método HET-CAM. O HET-CAM avalia basicamente alterações vasculares e gera resultados que, por sua vez, quando comparados ao modelo animal, têm grande relação com fenômenos observados na conjuntiva. Como no teste de irritação ocular de Draize, as lesões de conjuntiva têm um peso menor em termos de MEM, do que as lesões de córnea e íris; podemos dizer que os efeitos detectados no HET-CAM apresentam, via de regra, peso menor do que as alterações detectadas em outros sistemas como, por exemplo, aquelas induzidas em órgãos isolados.

Por fim, vale ressaltar que a perspectiva de substituir o teste de irritação ocular de Draize por uma estratégia in vitro requer o conhecimento dos modelos envolvidos, incluindo o melhor conhecimento dos mecanismos da irritação ocular, e, para isso, estudos adicionais aos que existem disponíveis hoje na literatura são necessários. O principal desafio dos setores industriais e regulatórios que apresentam interesse no tema é desenvolver tal estratégia de avaliação, que só será construída com base no conhecimento científico. 


\section{Conclusões}

Os resultados obtidos nos permitem concluir que:

- Tanto o RBC como o HET-CAM são ensaios viáveis e de fácil realização quando comparados ao teste de Draize;

- O método HET-CAM tende a superestimar resultados obtidos in vivo;

- Dentre os dois métodos in vitro, o RBC foi o que apresentou melhor concordância com o teste de Draize;

Para a avaliação final quanto à aplicabilidade dos testes RBC e HET-CAM, será necessária a realização de novos ensaios, contemplando um número maior de ingredientes e produtos acabados pertencentes a diferentes categorias, como e.g. colírios, cosméticos etc.

\section{Assessment of ocular irritation potential of cosmetic's ingredients using the Draize test, Het-Cam and RBC}

\section{Abstract}

The Draize test, usually applied to assess ocular irritation potential, has been criticized in terms of its ethical acceptability and its scientific validity. However, there is no universally applicable validated non-animal alternative to this in vivo test. Hence, the goal of our study was to evaluate the in vivo effects of surfactants in comparison to RBC and HET-CAM assays. Eight surfactants were evaluated in vivo and those substances were studied using RBC (defibrinated sheep blood) and HET-CAM (ten-day-old fertilized eggs) assays. Concerning the comparison of in vitro assays to the Draize test, our results indicate that: (i.) both RBC and HET-CAM are feasible assays, (ii.) HET-CAM seems to induce false positive responses, and (iii.) RBC presents better concordance of results than HET-CAM. Additional studies involving a greater number of ingredients must be performed in order to confirm the applicability of $\mathrm{RBC}$ and HET-CAM assays as alternatives to the Draize test.

Keywords: Alternative methods. Eye irritation. Quality control. Health surveillance. 3R's. 


\section{Referências}

ABREU, C. L. C. Avaliação de citotoxicidade induzida por produtos cosméticos pelo método de quantificação de proteínas totais em células 3T3. $122 \mathrm{f}$. Dissertação (Mestrado)-Instituto Nacional de Controle da Qualidade em Saúde, Fiocruz. Rio de Janeiro. 2008.

ABREU, C. L. C.; PRESGRAVE, O. A. F.; DELGADO I. F. Metodologias alternativas à experimentação animal: aplicação no controle da qualidade de produtos sujeitos à ação da Vigilância Sanitária. Revista do Conselho Federal de Medicina Veterinária, [S.l.], v. 45, p. 20-27, 2008.

ADRIAENS, E. et al. Successful prevalidation of the slug mucosal irritation test to assess the eye irritation potency of chemicals. Toxicology in vitro, [S.I.], v. 22, n. 5, p. 1285-1296, 2008.

ALVES, E. N. et al. Comparative study of three in vitro methods for assessment to eye potential irritation. Revista Brasileira de Toxicologia, [S.l.], v. 18, p. 102, 2005.

ALVES, E. N. et al. A reassessment of the in vitro $\mathrm{RBC}$ haemolysis assay with defibinated sheep blood for the determination of the ocular irritation potential of cosmetic products: comparison with the in vivo. Draize rabbit test. Alternative to Laboratory Animals, [S.l.], v. 36, n. 3, p. 275-284, 2008.

BOTTING, J. The history of thalidomide. Drug News Perspectives, [S.l.], v. 15, n. 9, p. 604-611, 2002.

CORRADO, M. Uso do método Het-CAM como modelo alternativo ao teste de irritação da mucosa oral de hamsters na avaliação do potencial tóxico de dentifrícis. 105 f. Dissertação (Mestrado)-Instituto Nacional de Controle da Qualidade em Saúde, Fiocruz. Rio de Janeiro. 2007.

COSTA, R. N. Estudo da aplicabilidade do ensaio de quantificação de proteínas totais em células SIRC na avaliação do potencial de irritação ocular de xampus e tensoativos. $61 \mathrm{f}$. Dissertação (Mestrado)-Escola Nacional de Saúde Pública Sérgio Arouca, Fiocruz. Rio de Janeiro, 2006.

DEBBASCH, C. et al. Eye irritation of low-irritant cosmetic formulations: correlation of in vitro results with clinical data and product composition. Food and Chemical Toxicology, [S.1.], v. 43, p. 155-165, 2005.

DE TORRES, E. P.; LARRAURI, A. G.; KUHN, G. R. Ensayos alternatives a la experimentación animal. Animales de Experimentación, [S.l.], v. 3, n. Suppl. 2, p. 30-36, 1997. 
DRAIZE, J. H.; WOODARD, G.; CALVERY, H. O. Methods for the study of irritation and toxicity of substances applied topically to the skin and mucous membranes. Journal of Pharmacology and Experimental Therapeutics, [S.1.], v. 83, p. 377-390, 1944.

ESAC STATEMENT. Scientifically Validated Methods: the Bovine Corneal Opacity and Permeability (BCOP) and the Isolated Chicken Eye (ICE) test methods for eye irritation. Disponível em: <http://ecvam.jrc.it>. Acesso em: 26 jan. 2009.

GERNER, I.; LIEBSCH, M.; SPIELMANN, H. Assessment of eye irritation properties of chemicals by applying alternatives to the Draize rabbit eye test: the use of QSARs and in vitro tests for the classification of eye irritation. Alternatives to Laboratory Animals, [S.1.], v. 33, n. 3, Suppl., p. 215-237, 2005.

HAGINO, S. et al. Interlaboratory validation of in vitro eye irritation tests for cosmetic ingredients. (2) Chorionallantoic Membrane (CAM) test. Toxicology in vitro, [S.1.], v. 13, p. 99-113, 1999.

ILAR. Science, medicine and animals. [S.1.]: The National Academies Press, 2004.

JOURNAL OFFICIEL DE LA REPUBLIQUE FRANÇAISE. Aretê du 27 decémbre 1996 relatif aux méthodes d'analyse nécessaires au controle de la composition dês produits cosmétiques. Annexxe IV: méthode officialle d'évaluation du potencial irritant par application sur la membrane chorioallantoidienne del'oeuf de poule, 1996. p. 19137-19138.

KAY, J. H.; CALANDRA, J. C. Interpretation of eye irritation tests. Journal of the Society of Cosmetic Chemistry, [S.1.], v. 13, p. 281-289, 1962.

LAGARTO, A. et al. Comparative study of red blood cell meted in rat and calves blood as alternatives of Draize eye irritation test. Toxicology in vitro, [S.1.], v. 20, n. 4, p. 529-533, 2006.

MACKLIS, R. M. Radithor and the era of mild radium therapy. JAMA, v. 264, n. 22, p. 2870, 1990.

MEHLING, A.; KLEBER, M.; HENSEN, H. Comparative studies on the ocular and dermal irritation potential of surfactants. Food and Chemical Toxicology, [S.1.], v. 45, n. 5, p. 747-758, 2007. 
MITJANS, M.; INFANTE, M. R.; VIANRDELL, M. P. Human hemoglobin denaturation as an alternative to the Draize test for predicting eye irritancy of surfactants. Regulatory Toxicology and Pharmacology, [S.1.], v. 52, n. 2, p. $89-93,2008$.

NORTH-ROOTH, H. et al. Evaluation of an in vitro cell toxicity test using rabbit corneal to predict the eye irritation potential of surfactants. Toxicology Letters, [S.1.], v. 14, p. 207-212, 1982.

PAPE, W. Protocolo 37. [S.l.]: Red Blood Cell Test System INVITTOX, 1992.

PROCEDIMENTO operacional padrão POP no 653330.004. In: INCQS. Manual da qualidade, ensaio de irritação ocular. Rio de Janeiro, 2005.

SHOPSIS, C.; ENG, B. Rapid cytotoxicity testing using a semi-automated protein determination on cultured cells. Toxicology Letters, [S.1.], v. 26, Suppl. 1, p. 1-8, 1985.

TAKAHASHI, Y. et al. Development of the short time exposure (STE) test: an in vitro eye irritation test using SIRC cells. Toxicology in vitro, [S.1.], v. 22, n. 3, p. 760-770, 2008.

TANI, N. et al. Interlaboratory validation of the in vitro eye irritation tests for cosmetic ingredients. (8) Evaluation of cytotoxicity tests on SIRC cells. Toxicology in vitro, [S.1.], v. 13, p. 175-187, 1999.

TAVASZI, J.; BUDAI, P. The use of HET-CAM test in detecting the ocular irritation: communications. Agricultural and Applied Biological Sciences, [S.1.], v. 72, n. 2, p. 137-141, 2007.

VIAN, L. et al. Comparison of three in vitro cytotoxicity assays for estimating surfactant ocular irritation. Toxicology in vitro, [S.1.], v. 9, Suppl. 2, p. 185$190,1995$.

WAX P. M. Elixirs, diluents, and the passage of the 1938 Federal Food, Drug and Cosmetic Act. Annals of Internal Medicine, [S.1.], v. 122, n. 6, p. 456$461,1995$.

WILHELMUS, K. R. Therapeutic revieus: the Draize eye test. Survey of Ophthalmology, [S.1.], v. 45, n. 6, p. 493-515, 2001. 
Universitas: Ciências da Saúde., Brasília, v. 6, n. 2, p. 103-120, jul./dez. 2008
Andréa M. Nóbrega, Eloisa N. Alves, Rosaura F. Presgrave, Isabella F. Delgado

YANG, W.; ACOSTA, D. Cytotoxicity potential of surfactants mixtures evaluated by primary cultures of rabbit corneal epithelial cells. Toxicology Letters, [S.1.], v. 70, p. 309-318, 1994.

\section{Agradecimentos}

Andréa Martins da Nóbrega é bolsista PIBIC (CNPq/Fiocruz). O estudo recebeu auxílio financeiro do PDTSP-SUS/Fiocruz e do Edital MCT/ CNPq 14/2008. 